Changes in Japanese Ski Resorts with the Development of Inbound Tourism: A Case Study of Niseko-Hirafu District, Hokkaido

\title{
Masaaki Kureha
}

Faculty of Life and Environmental Sciences, University of Tsukuba,

Tennodai 1-1-1, Tsukuba, Ibaraki, 305-8572, Japan

+81-298-53-4401, mkureha@geoenv.tsukuba.ac.jp

Masaaki Kureha is a Professor of regional geography at the University of Tsukuba. He received his Doctor of Philosophy from the University of Innsbruck, Austria. His academic interests cover regional aspects of tourism, ranging from ski tourism and rural tourism both in Japan and in the Alps to changes in European tourism through the transformation of former Eastern Europe. He has published many books, including “Wintersportgebiete in Österreich und Japan” (Institute of Geography, Innsbruck), “Alsace and Lorraine in the period of European integration” (Ninomiya-Shoten, Tokyo), and “The enlargement of the EU and new Europe” (Hara-Shobo, Tokyo).

Total words: 3500

Number of figures: 6 

Changes in Japanese Ski Resorts with the Development of Inbound Tourism: A Case

\author{
Study of Niseko-Hirafu District, Hokkaido
}

\title{
Abstract
}

This study examines the recent changes in Japanese ski resorts brought about by the development of inbound tourism, analyzing landscape changes in the Niseko-Hirafu District, Hokkaido. Over the last 20 years, many ski resorts have faced hardships, with the number of skiers steadily declining since the early 1990s. However, since the mid-2000s, several resorts have attracted foreign skiers from specific markets. The Niseko region of Hokkaido appeals to many winter skiers from Australia, as well as Asian tourists from Hong Kong and Singapore. Many apartment buildings have been constructed near its ski bases since 2005. In most cases, Australians own such apartments-mostly cottages in refined Western styles, rather than condominiums. The apartments are rented out for long stays and command relatively higher prices; they are usually used by the owners and by foreign tourists brought in through firms managed by Australians.

Keywords: inbound tourism, Japan, landscapes, Niseko, ski resorts 


\section{Introduction}

Inbound tourism in Japan developed around 2000, and was aggressively promoted. The remarkable buzz of international tourism around Japan gave rise to a new policy on international tourism, which aimed to increase inbound tourism to certain markets. Consequently - except in the wake of some exceptional events such as the Lehman Brothers' bankruptcy and the 2011 Tohoku earthquake - the number of tourists from Asian countries has been growing. Most foreign tourists tend to be interested in visiting famous Japanese cultural icons like shrines, temples, and old-town landscapes. Shopping also is an important activity. It is especially common for Chinese people who visit Japan for the first time in organized tours (Jin 2009). However, some tourists opt to spend time on special interests such as skiing, golf, or exploring popular Japanese culture. Some tourism forms are already famous in Japan—golf tourism for Koreans, skiing for Australians, and content tourism for Western tourists, based on manga (comic books), novels, films, and more.

However, Japanese ski tourism has stagnated since the mid-1990s with the numbers of skiers in decline. This contrasts against the boom between 1981 and 1993 where the numbers of skiers increased from 8.6 million in 1981 to a peak of 17.7 million in 1993 according to data from the Leisure Development Center (Kureha 2004, 2005). Since 1995, most ski fields 
have faced multiple problems—decreasing numbers of skiers, reduced service of ski lifts, and frequent management changes or bankruptcies of ski lift companies (Kureha 2008). In the face of these challenges, most ski lift companies have undertaken various efforts to maintain the numbers of skiers. However, around a quarter of the total number of ski fields have already closed down (Kureha 2009). At present, global warming is also a major concern for many ski destinations worldwide. However, in Japan it is not as serious a problem as compared with locations such as the European Alps (Agrawala 2007); instances of ski fields in Japan closing down due to lack of snow depth are rare.

Following a trend, many ski resorts are now trying to attract international tourists as new markets develop. Some have already seen a rise in the number of foreign skiers from Australia and other countries. As a result, significant changes can now be seen in such ski resorts, especially in their landscape. These changes are dominant in the Niseko area in Hokkaido and the Happo-one area in Hakuba (Nagano). The Niseko area, which is famous among Australian skiers (and recently, Asian skiers, too) for its good quality snow, has had remarkable landscape changes over the last 10 years with large numbers of newly constructed accommodations. This study focuses on inbound ski tourism in the Niseko-Hirafu District at the foot of Mt. Niseko Annupuri. 
There have already been some studies on new tourism trends in the Niseko area. Various study disciplines have dealt with the area's changing tourism from different perspectives. For example, Ichioka et al. (2009) examine the growing trend of inbound tourism in Niseko and point out the local changes brought about by foreign tourists. Other researchers are interested in the spurt of foreign investment influencing Niseko (Kikuchi 2009). Uesaki (2009) focuses on the local government's designation process of the landscape conservation district (Kutchan-Cho). There have been some smaller studies on how Niseko's landscape has changed since 2000, but they do not fully capture the drastic landscape changes made over a short period, especially in the Niseko-Hirafu District. Yamakawa (2011) analyzes the "language landscape” in Kutchan-Cho by studying the signboards along main streets, witnessing the emergence of English illustrations. Ozawa and Ikemura (2011) describe the development of the Niseko-Hirafu District as a ski resort, analyzing land use, land ownership, and internal differences in spatial features. However, their study emphasizes the changes over a long time, namely since the Meiji Era, and includes few details of recent landscape changes.

Generally, in a base district of a ski field, there is a spatial concentration of ski resort facilities, such as accommodations, restaurants, ski rental shops, etc. This landscape changes 
for various reasons such as developers’ plans, local and regional government policies, visitor trends, and more. Therefore, an analysis of this landscape makes it possible to assess the changes in the total space of a ski resort. Landscape changes have been an important viewpoint for analyzing resort development in geographical studies. Barker (1982) revealed the east-west differences of resort development processes in the Alps, examining landscape change in the alpine rural areas. In the case of the Niseko-Hirafu District, as compared to other ski resorts in Japan, we see new landscape elements primarily characterized by imported architectures of buildings used as lodging facilities. This study examines those landscape changes.

\section{Purpose of the Study and Methods}

This study examines the recent changes in ski resorts caused by the development of inbound tourism in Japan, analyzing landscape changes in the Niseko-Hirafu District, Hokkaido. The influence of redeveloped ski resorts on changes in neighboring landscapes can be noted by, among other things, the appearance of new-style accommodations.

The study field, Niseko-Hirafu District, administratively belongs to Kutchan-Cho in Hokkaido (Figure 1). Niseko-Hirafu District is located at the base of the Niseko Mountain Resort Grand Hirafu Ski Field, one of the biggest ski fields in Japan. Niseko's name is 
derived from Mt. Niseko Annupuri, which currently has five ski fields on its hillsides: Niseko Mountain Resort Grand Hirafu and Niseko Hanazono on the eastern slope, and Niseko Village, Niseko Annupuri International Ski Resort, and Moiwa Ski Resort on the southern slope.

In the study, I first analyze the historical changes in the Niseko-Hirafu District as an important ski resort, mainly based on previous studies regarding Niseko. Second, I analyze the landscape changes using various materials. The data on present land use is derived from my own survey. Data on previous land use is derived from residential maps, on which each building mapped is labeled with the name of the resident or company (or accommodation) occupying it; such maps are unique to Japan. This data is supplemented with aerial photographs and information from previous guidebooks. This study also uses data from applications for building permission from the local government (Kutchan-Cho). These unpublished data provide the start dates of construction of new accommodations. "New accommodation” in this paper is defined as a unit that comprises of an independent living room, bedrooms, kitchen, and bathroom—called "apartment" in English, "Ferienwohnung" in German, and "appartement" in French. A furnished unit in a building or a house is rented for the temporary use of tourists as an alternative to a normal lodging facility such as a hotel. 
These new accommodations are preferred by long-stay vacationers. They are classified as “condominiums" or "cottages," depending on their structure. The outward appearance of the condominium is similar to an urban apartment. For this study, buildings having more than four-floors or having more than ten units in total, are considered condominiums. Cottages are single two- or three-story houses having one or more units.

The paper first discusses the changes in Japanese ski resorts. It then addresses the causes of these changes from a geographical perspective. Finally, landscape feature changes are discussed as part of the change in Japanese ski resorts and the change in the culture of ski tourism in Japan.

\section{Historical Background of the Niseko-Hirafu District}

In the Niseko-Hirafu District, settlers first started cultivation around 1890 (Committee for Publishing a History of Ski Resort Development at Hirafu 2011). In 1897, an accommodation featuring a hot spring (Yamada Onsen) opened near the settlement at a time when many hot spring resorts were being developed around Mt. Niseko-Annupuri. In 1912, Austrian military officer Theodor von Lerch, who is said to be the father of skiing in Japan, taught ski techniques in Kutchan-Cho and tried to climb nearby Mt. Yōtei. Many skiers visited the resort to ski or compete, attracted by the depth of snow and good railway conditions between 
Hakodate and Otaru. Around 1930, this area was nicknamed the "St. Moritz of the Orient."

However, technical development only came to this area in 1961, with the introduction of ski lifts. Many ski fields elsewhere in Japan had already been equipped with lifts. Then farmers around the ski field in Niseko-Hirafu (today: Niseko Mountain Resort Grand Hirafu) opened their own accommodations to lodge skiers, supplementing the guesthouse at Yamada Onsen. They privately managed the accommodations, called "minshuku,” on a small scale, and tried to increase the capacity gradually. Thereafter, various accommodations, including hotels and ryokan (Japanese style inns), sprang up in the quarter (the Center Village today) between the base of the ski field and a prefectural road (Route 343).

Many pensions, small resort inns in the Western style, have opened since 1980, forming clusters (called "Pension Village” today). Some frequent visitors settled in Hirafu from urban areas and started to manage western-style inns in the lower quarter, located southeast of the prefectural road. Pensions were also constructed in Izumikyo, where an estate company has sold lots for pensions and second homes since 1985 in three separated estates (Figure 1). Thus, the Niseko-Hirafu District expanded spatially with the help of the "ski tourism boom" around 1990. During this boom, many skiers came to Niseko not only from Hokkaido, but also from all over Japan. The ski field was transformed through renovations and ski trail 
expansions (the Niseko Hanazono ski trail). Many primitive ski lifts were replaced with new high-capacity ones such as quad lifts and gondola lifts.

However, since the mid-1990s, the number of ski visitors to Niseko has gradually decreased, following the general trend across Japan. In response to this decline, the ski lift company stopped operating some of the lifts. Also, a few pensioners withdrew from management of their inns. Despite this declining trend, visits by Australian skiers have risen remarkably since around 2000. Before this skiing breakthrough, around 1995, some Australians started a river rafting business operating during the summer on Niseko's rivers. Today we can also see an increase in the number of skiers from Asian countries such as Hong Kong and Singapore. Foreign tourists clocked 230,000 nights of the total 800,000 nights in Kutchan-Cho in fiscal year 2012.

\section{Land Use Analysis}

Figure 2 shows the distribution of buildings and their uses in the Niseko-Hirafu District in 2012 based on data collected through fieldwork. The important landscape elements considered are apartments—comprising condominiums (Figure 3) and cottages (Figure 4) - hotels and pensions, second homes or rental houses, and restaurants. The most remarkable element is apartments of various sizes, with the largest units reaching over 100 
square meters.

Condominiums are located near the ski field base and are in four- to six-story buildings.

The biggest one, in the Center Village, contains 80 units. Mainly, two- to three-story cottages are located in the Pension Village and Izumikyo, often having peculiar facades. For example, concrete buildings abound, displaying cubic or wooden (board or log) facades with brown or black color and glass. These facades are quite new in Japan and do not conform to the landscape of the existing Japanese ski resorts. The apartments usually command very high purchase prices, as most people see them as investments.

When owners are not using their facilities, the apartments are often leased as accommodation through intermediate agents, usually Australians. Here, too, the price for accommodation is high—over 15,000-20,000 Yen per person per night during the high season. Usually, these accommodations are used for weeklong stays, with meals not included. The lodging culture is quite different from that of the Japanese, who tend to stay for short periods (one or two days, three days maximum) with at least two daily meals (dinner and breakfast) included in the price.

The Center Village shows a mixed landscape comprising not only apartments, but also hotels, pensions, second homes, restaurants, rental shops, and real estate offices. Most 
commercial facilities are located along the main streets. Contrarily, in the Pension Village, cottages dominate the landscape, with some pensions and restaurants also located there.

\section{Process of Landscape Changes}

The number of Australian skiers has grown since 2000, when ski-tourism related business began with some Australian immigrants who had already engaged in a river-rafting business on Niseko's river around five years. However, there was a lack of accommodation suitable for Australians, who preferred a long stay. Similar to the general trend in ski related accommodations in Japan, some accommodations in Niseko also faced management difficulties due to the declining number of skiers in the late 1990s. Some closed shop and others decided to sell. Since that time, some Australian companies (Hokkaido Tracks, SkiJapan, The Niseko Company, etc.) have constructed apartments for Australian use.

Here, I examine when these new apartments were built, using the applications for building confirmation filed with the local government (Kutchan-Cho). The data show the start of construction, not completion, but are enough to gauge the general trends.

Figure 5 illustrates the applications for building in the Center Village and the Pension Village. There are 189 apartments in these two villages, of which 151 were constructed roughly between 2004 and 2011 (Figure 5) and the remaining 38 were conversions from 
previous accommodations. Peak construction was between 2006 and 2008, when the quantity of foreign-owner applications was the greatest. Construction expanded from the neighborhood of the ski fields to remote places such as the Pension Village, Izumikyo, and a new cottage village-Country Resort-located $3.5 \mathrm{~km}$ from the ski field (outside of the Figure 5 map) comprising 40 to 50 relatively large cottages. Today, owners from Hong Kong, Singapore, and Malaysia can be found, along with Australian owners. When owners are not using their apartments, tourists can use it through the intermediation of specific firms, usually managed by Australian owners. Today, foreign owners hold about $80 \%$ of the total number of apartments.

\section{Land Use before the Apartments}

In most cases, apartments were constructed on vacant lots. Before and during the boom period, many vacant lots were slated for the construction of accommodations or second homes. With the large number of vacant lots in Hokkaido, some unscrupulous real-estate developers participated in selling smaller lots of worthless property (a process called genya shōho). However, even in the boom period, there were many unused lots because of the locational disadvantages of Niseko, which is far from metropolitan areas such as Tokyo, or even Sapporo. Australian developers used such lots to build their apartments. 
In other instances, new apartments were built on the sites of closed accommodations or unused second homes, built after tearing down the previous constructions. Pensions also played an important part in the proliferation of apartments. As mentioned earlier, in the 1980s, many pension owners moved to the region from urban areas to begin managing these accommodations and to enjoy living in a natural environment. As most of them came to Niseko in their 40s, by the early 2000s they were approaching 70 years old; they were on the verge of retirement. However, their children did not want to inherit the pensions because they saw their parents struggle with an excessive workload. At the same time, there was growing demand for real estate for apartments. In response, some operators decided to sell or rent their buildings or sites.

In 1995, there were 91 lodging facilities in the area (Figure 6). Only a third of those were continuously managed in 2012, with an additional five cases transferred to another management firm. There are 25 cases of conversion into apartments, mostly in the Pension Village. An additional ten cases were vacant lots in 2012, of which many were sold to build apartments.

However, the growing construction trend threw up various problems, including clashes in the appearance between the new and older building in terms of color and height, 
inadequate snow-removal facilities, and more. Deforestation was increasing because many apartments were developed on lots that had been covered by woods. While most of the existing accommodations (ryokan and pensions) were two-story houses, condominiums with five- or six-stories were constructed, mainly near the ski base. In the Pension Village the dominant type of building was a small two-story house with brown wooden board walls and a gabled roof. The new cottages stood out terribly on the landscape with their use of concrete, black or glass walls, and their cubic form. Many of these new houses stood out above the pensions with three or four floors. Some of the new houses were built without any consideration for the heavy snow in this region.

Only since February of 2008 did the local government (Kutchan-Cho) enforce regulations on construction, concerning height, coverage, color, and design. Today, there are four regulations in force with regard to quasi-urban planning, landscape, land use, and landscape conservation. However, while the upper quarter of Central Village is conserved as a quasi-national park (Niseko-Shakotan-Otaru Kaigan Quasi-National Park), the regulations for building construction have relaxed since 2012 due to the realization of land use for the quarter located in the place most accessible from the ski field.

\section{Discussion and Conclusion}


The Niseko-Hirafu District has experienced a drastic landscape change in recent years. This is recognized as an exceptional case among ski resorts in Japan, which generally are either stagnant or in a decline today. The experience of Niseko demonstrates that the development of international tourism can bring an opportunity to regenerate stagnant ski resorts in Japan.

An important factor in Niseko's changes was the availability of many vacant lots, lots that were not fully developed even during the boom period because of their distance from metropolises. Many additional lots were also derived from the closing of accommodations that had been managed primarily by immigrants from urban areas. The short history of settlements in Hokkaido also affected the availability of land in Niseko. Locals, even farmers, were willing to move out and sell their property. This feature of Hokkaido is quite different from the other main islands of Japan, where farmers' lands usually stay in one family, inherited from generation to generation.

Niseko's natural conditions also play an important role in its development, with its powder snow, greater snow depth, and beauty. Niseko has become an alternative destination for Australian skiers since the September 11 attacks in the US and is one of the biggest ski resorts in East Asia.

There may be some conflicts in terms of landscape and skiing cultures. Today, the 
landscape in the Niseko-Hirafu District is characterized as a resort enclave (Pearce 1995). This is because of its foreign atmosphere, the dominance of new style buildings and English signboards, and because much of the economic benefits flow into foreign countries. Many lodging facilities, restaurants, and ski lift facilities are now owned by foreigners-people who do not always live in Niseko and only have a business base there. While there are many foreign guests today in Niseko, large portions of the rewards of consumption flow into the countries of the entrepreneurs. Therefore, Niseko now experiences a situation similar to resort enclaves in tropical beaches in the 1980s or 1990s. Japanese skiers tend to have some difficulty staying in these enclaves because of the difference in Japanese and Australian skiing customs.

The culture of Japanese ski tourism is different from that of Australia or other Western countries. The Japanese prefer short stays (two to three nights at the longest) with two meals (dinner and breakfast) a day included in the price of accommodation. This is different from the Australians, who stay a week or more in relatively larger accommodations equipped with furniture from their own country. They enjoy skiing only in good weather, prefer breakfast by themselves, and go out at night for après-ski. These preferences are reflected in the landscape in the Niseko-Hirafu District. 
During the past few years, some Australians have left Niseko and moved to other ski resorts, such as Hakuba or Nozawa Onsen in Nagano Prefecture (in central Japan) where they continue to enjoy Japanese culture within the ski resort. As the Niseko-Hirafu District is isolated from Kutchan-Cho city, which is six or seven km away, foreign tourists cannot easily access Japanese culture. (Although, the local government has introduced a nightly bus service between the areas.) This leads to a cultural isolation of the district as there are no active cultural exchanges between tourists and locals. In the future, such cultural exchanges will play an important role in the sustainable development of Niseko as an international ski resort.

In general, the Niseko-Hirafu District will continue to have advantages for potential development due to the good condition of the ski slopes with plenty of powder snow and the area's well-equipped apartments. The Niseko area should continue to be one of the most important destinations for Southeast Asian tourists whose interest in Hokkaido will grow in the near future.

\section{References}

Agrawala, Shardul, ed. 2007. Climate Change in the European Alps: Adapting Winter Tourism and Natural Hazards Management. Paris: OECD. 
Barker, Mary L. 1982. Traditional Landscape and Mass Tourism in the Alps. Geographical Review 72: 395-415.

Committee for Publishing a History of Ski Resort Development at Hirafu. 2011. Niseko Paudā Hisutorī [A History of Powder Skiing in Niseko]. Tokyo: Jitsugyo no Nihon Sha.

Ichioka, Hiroko, Mitsuhiro Kawamura and Yoshichika Narisawa. 2009. "Niseko Chiiki eno Inbaundo no Dōkō to Tenbō nitsuite no Kōsatsu” [A Study on Trends and Outlook for Inbound Tourism Markets to the Niseko Area]. Journal of Urban Studies 46: 19-26.

Jin, Yushi. 2009. “Nippon ni okeru Chūgokujin Ryokōsha Kōdō no Kūkanteki Tokuchō” [Spatial Characteristics of Chinese Tourist Activities in Japan]. Geographical Review of Japan 82: 332-345.

Kikuchi, Tatsuo. 2009. “Niseko Sukī Kankō Chiiki ni okeru Gaikoku Shihon no Shinshutsu to Keikaku Naiyō no Eikyō” [Influences of Foreign Investments and Their Development Plans in Niseko Ski Tourism Region]. Annals of Institute of Tourism Studies 8: 23-31.

Kureha, Masaaki. 2004. “Changes in the Regional Pattern of Ski Tourism in Japan.” Pp. 61-67 in 3rd FIS Ski History Conference, ed. Winter Sport Museum Mürzzuschlag. Mürzzuschlag: Winter!Sport!Museum.

Kureha, Masaaki. 2005. “Development of Ski Areas in Rural Mountainous Regions in Japan.” 
Pp. 137-142 in Internationale Skihistoriographie und deutscher Skilauf, ed. Gerd Falkner. Planegg: Deutscher Skiverband.

Kureha, Masaaki. 2008. “Changing Ski Tourism in Japan: From Mass Tourism to Ecotourism?” Global Environmental Research 12: 137-144

Kureha, Masaaki. 2009. "Nippon ni okeru Sukī Kankō no Suitai to Saisei no Kanousei” [The Possibility for Sustainable Development of Ski Tourism in Japan]. Geographical Sciences 64: 168-177.

Ozawa, Takeo and Nana Ikemura. 2011. "Hokkaido ni okeru Sukījō ni rinsetsusuru Chiiki no Keisei Katei to Kūkan Kōsei, Niseko-Hirafu Chiku wo Jirei toshite” [Development Process and Space Composition in the Region Adjacent to Ski Slopes in Hokkaido: A Case of Niseko-Hirafu District]. Journal of Architecture and Planning 76(662): 843-850.

Pearce, Douglas. 1995. Tourism Today: A Geographical Analysis, 2nd Edition. Harlow: Longman.

Uesaki, Hajime. 2009. “Keikan Seisaku Ryōiki ni okeru Chihou Jichitai no Henka ni tsuite, Kutchan-Cho oyobi Niseko-Cho ni okeru Keikan Chiku Shitei wo Daizai toshite” [The Change of the Local Government in the Landscape Policy]. Kinkidaigaku Hogaku: The law review of Kinki University 57(3): 1-39. 
Yamakawa, Kazuhiko. 2011. "Hokkaido Kutchan-Cho no Gengo Keikan to Chiiki Rūru nitsuite” [On the Language Landscape and Local Rule in Kutchan-Cho, Hokkaido]. Bulletin of Reitaku University 93: 137-156. 
Kureha

List of Figures

Figure 1 Study field

Source: Topographic map by the GSI (Geographical Survey Institute)

Figure 2 Distribution of buildings and their use in Niseko-Hirafu District in 2012

Source: Author's survey

Figure 3 Condominiums in Central Village

Source: Author's, Febrary 2013

Figure 4 Cottage in Pension Village

Source: Author's, Febrary 2013

Figure 5 Application-year for apartment building in the Center Village and the Pension Village

Source: The application for building permission from the local government (Kutchan-Cho) and Author's survey

Figure 6 Lodging facilities in 1995 and their present use in Niseko-Hirafu District Source: Author's survey, residential maps, aerial photographs and information from previous guidebooks. 


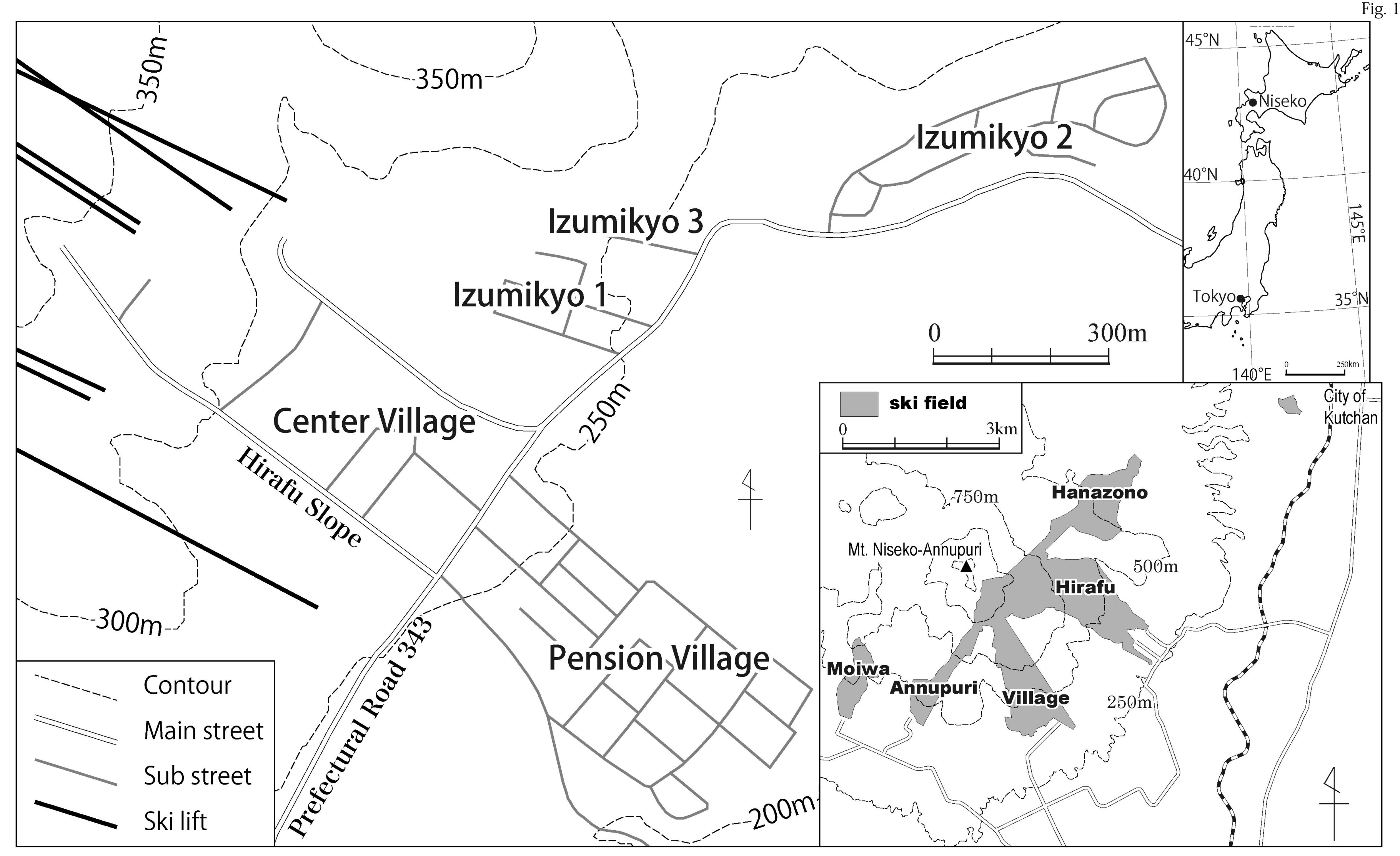




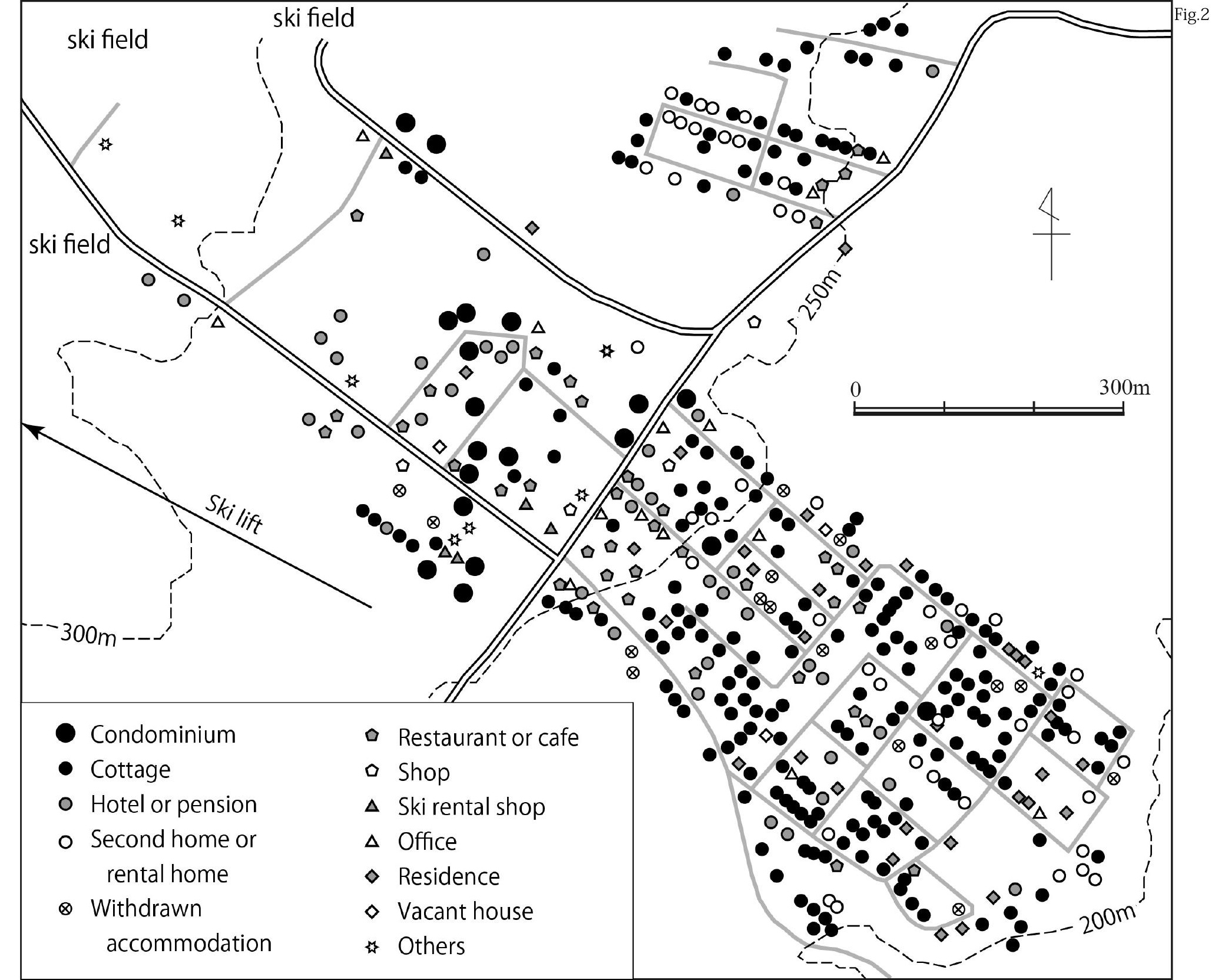




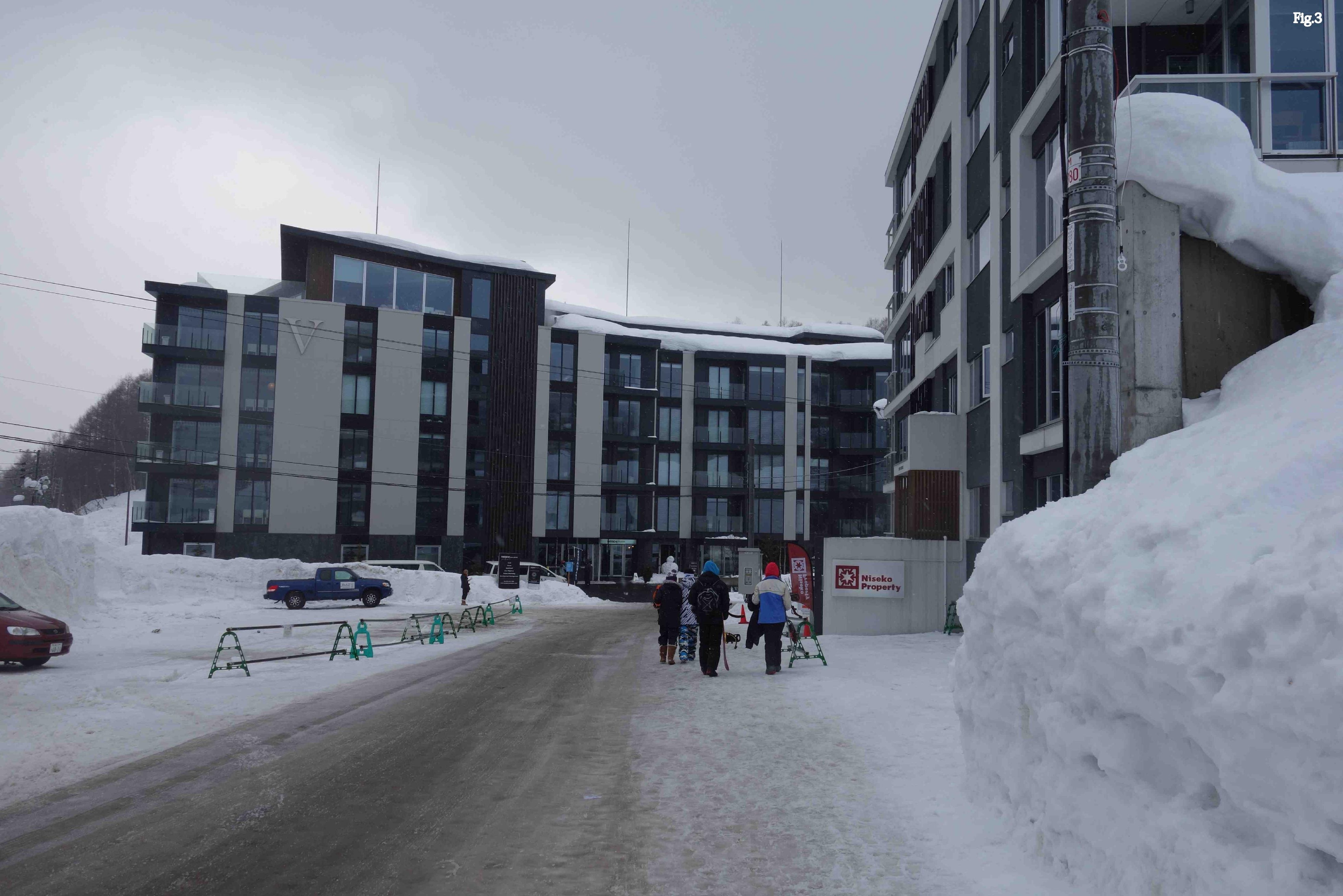




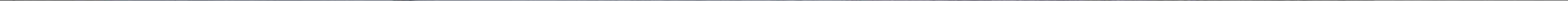




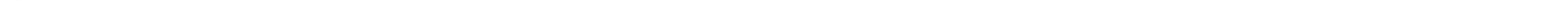




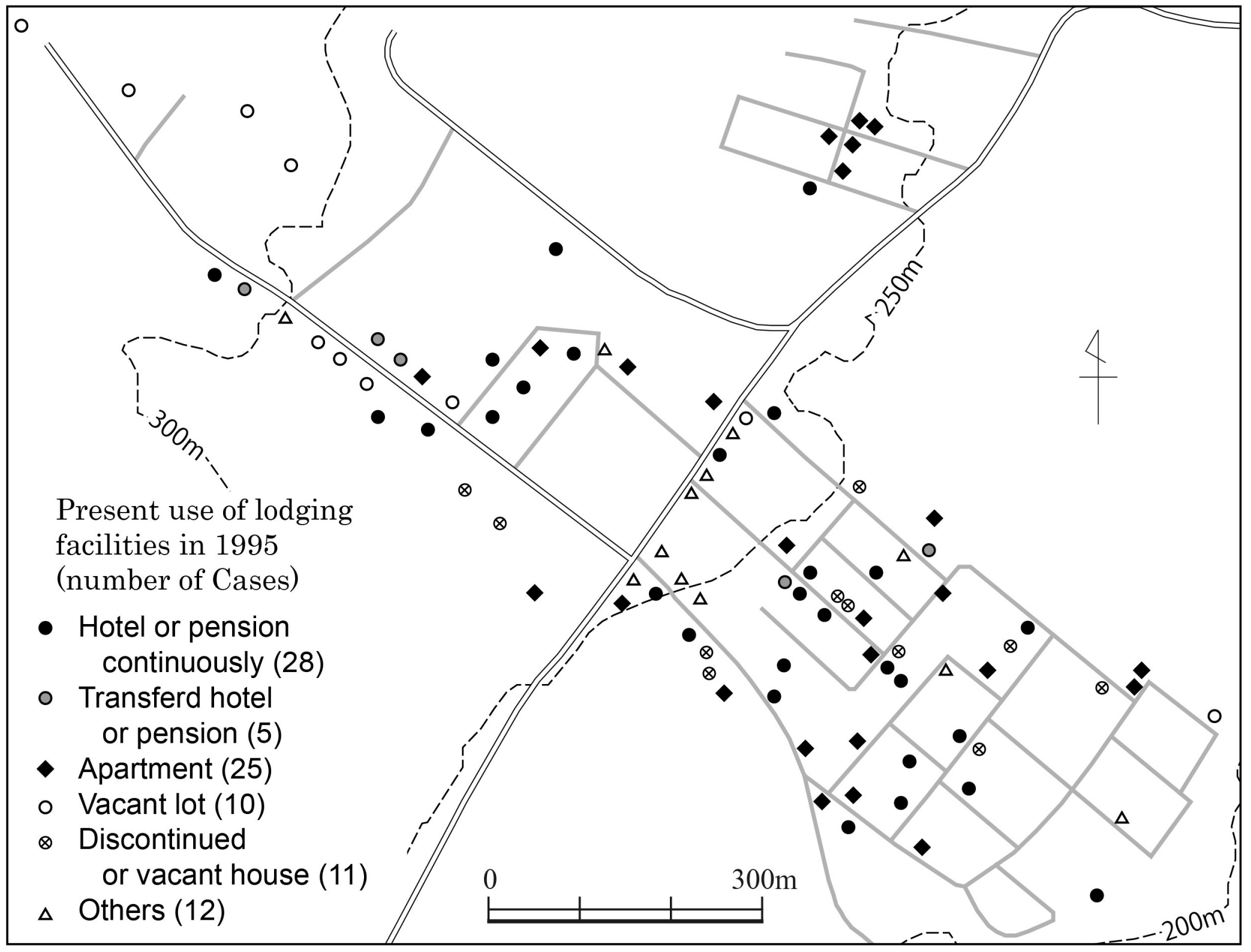

